\title{
Gérard A. Maugin: engineering scientist. Celebrating his 70th anniversary
}

Received: 27 September 2014 / Accepted: 2 October 2014 / Published online: 14 October 2014

(C) Springer-Verlag Berlin Heidelberg 2014

\section{The reasons for this tribute}

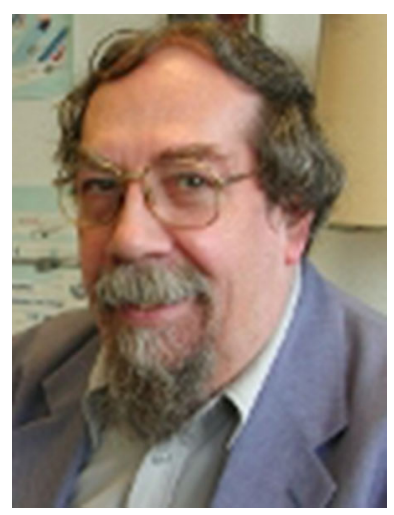

On Tuesday, March 18, 2014, a section of the EUROMECH Colloquium 563 was held to honor the contribution of Gérard Maugin to mechanical sciences. The interested scholars will be able to find at the Web site

$$
\text { http://www.memocsevents.eu/euromech563/ }
$$

a full list of contributed talks and will have an easy access to the files including their video recordings. Many among the pupils and co-workers of Prof. Maugin were present together with many scientists whose ideas and work were, and still are, influenced by his vision of mechanics and, in general, of science.

The first author of the present editorial, in that occasion, introduced Prof. Maugin, at first, by reading the following excerption from The Name of the Rose [by U. Eco, translated from the Italian by William Weaver, Warner (1980)]

I understood at that moment my master's method of reasoning, and it seemed to me quite alien to that of the philosopher, who reasons by first principles, so that his intellect almost assumes the ways of the

F. dell'Isola $(\varangle)$

Dipartimento di Ingegneria Strutturale e Geotecnica, Università di Roma La Sapienza, Rome, Italy

E-mail: fdellisola@me.com

F. dell'Isola

International Research Centre for Mathematics and Mechanics of Complex Systems, Università dell'Aquila, L'Aquila, Italy

J. Pouget · M. Rousseau

Institut Jean Le Rond d'Alembert Université Pierre et Marie Curie, Paris, France 
divine intellect. I understood that, when he didn't have an answer, William proposed many to himself, very different one from another. I remained puzzled. "But then ..." I venture to remark, "you are still far from the solution."..."I am very close to one," William said, "but I don't know which." ..." Therefore you do not have a single answer to your questions?" ..."Adso, if I did then I would teach theology in Paris." ..."In Paris do they always have the true answer?" ..."Never, "William said, "but they are very sure of their errors." ..."And you," I said with childish impertinence, "never commit errors?" ... "Often," he answered. "But instead of conceiving only one, I imagine many, so I become slave of none." I had the impression that William was not at all interested in the truth, which is nothing but the adjustment between the thing and the intellect. On the contrary, he amused himself by imagining how many possibilities were possible.

and then he continued by stating that:

Notwithstanding the fact that, undoubtedly, Gerard be a Professor from Paris, and even if he always showed the characteristic proud attitude of every French scientist in debates, seminars, lectures and discussions, I can witness that he was never sure of his errors. He is indeed one of the most open minded "savant" whom I had the possibility to meet. I could experience personally how he has been always open to new ideas, and ready to sincerely help the younger scientists toward their personal path to original scientific research. For this reason it is a great pleasure to dedicate to him this section of the EUROMECH Colloquium 563.

We proposed Prof. Kienzler to promote the present special issue, because we believe that the creative, innovative and indefatigable scientific work of Prof. Maugin deserves to be indicated as an example for younger generations.

\section{A short scientific biographical note}

Gérard A. MAUGIN was born in the west of France in December 1944.

$\mathrm{He}$ is an internationally recognized specialist in continuum mechanics and wave propagation: His scientific interests span nonlinear effect in mechanics, physics and biology, in particular, solitons, fracture, coupled electro-magneto-mechanical effects, media with microstructure and smart materials. He describes himself as a French mechanical-aeronautical engineer with an American education and a strong interest in mathematical physics.

He was basically educated in Paris (Mechanical Engineer, 1966; Aeronautical Engineer, 1968; MSc in Mathematics, 1968) and Princeton, USA (MA, 1969, PhD, 1971), and was granted his Doctorat d'État ès Sciences Mathématiques in Paris-6 in 1975. Director of Research at the Centre National de la Recherche Scientifique (Physical Sciences for Engineering), having been a motive power in the group on Continuum Mechanics at University of Paris-6 in the environment of Paul Germain, he became Head of the "Laboratoire de Modélisation en Mécanique", a large research unit devoted to all aspects of theoretical fluid or solid mechanics, at the Université Pierre et Marie Curie (UPMC) in Paris. Then, he created (2006) the "Institut Jean Le Rond d'Alembert" that gathered both theoretical and experimental studies in mechanics, acoustics and energetics, including such original fields as musical acoustics, in the renovated buildings of the UPMC. He also taught graduate courses (electromagnetic media, nonlinear waves, plasticity, fracture, configurational forces) in the same institution. He is emeritus in service since October 2010.

He has lectured on all continents, published about 350 refereed papers in journals of mathematical physics, theoretical mechanics and applied mathematics, contributed to some 200 proceedings of international conferences, and is the author or co-author of twelve monographs or textbooks including:

1. the pioneering Continuum Mechanics of Electromagnetic Solids (Elsevier, 1988, in Russian, Mir, 1991), the encyclopedic Electrodynamics of Continua (two volumes, Springer, New York, 1990, co-authored with A. C. Eringen; soft-cover reprint 2012),

2. the specialized monograph on Nonlinear Electro-Mechanical Couplings, (J. Wiley, 1992; co-authors J. Pouget, R. Drouot and B. Collet) the much focused textbook entitled Thermomechanics of Plasticity and Fracture (Cambridge, 1992; in Japanese, 2000),

3. the original Material Inhomogeneities in Elasticity (Chapman and Hall, 1993)—first book of its kind, and also

4. Nonlinear Waves in Elastic Crystals (Oxford Mathematical Monographs, 1999), 
5. The Thermomechanics of Nonliear Irreversible Behaviors (World Scientific, 1999), and recently

6. Numerical Simulation of Waves and Fronts in Inhomogeneous Solids (World Scientific, 2008, co-authored with A. Berezovski and J. Engelbrecht from Estonia),

7. the lengthy Configurational forces (CRC/Taylor and Francis, 2011), and a historical perspective in

8. Continuum Mechanics Through the Twentieth Century (Springer, 2013) and the Eighteenth and Nineteenth Centuries (Springer, 2014).

He has edited eleven volumes of proceedings of international conferences, e.g., the two-volume set Continuum Models and Discrete Systems (Longman, 1990), or volumes dealing with deformable electromagnetic bodies, waves or the mechanics of Cosserat continua (Springer 2010, 2011), and also special issues of journals such as Wave Motion, Mechanics Research Communications, and the International Journal of Engineering Sciences. He has been much active in the edition of these journals as well as in that of the International Journal of Electromagnetics and Mechanics (co-founded in 1991), the Journal Applied Archives of Mechanics and the Journal of Thermal Stresses. He generously contributed his expertise to the appraisal of scientific research programs in about ten countries. He never neglected more menial duties such as the review of published papers and the critical assessment of new books in theoretical mechanics or applied mathematics. He dutifully sat for 9 years on the national selection committee for admission and promotion of professional researchers at CNRS.

He was honored by several medals and prizes including: a CNRS Medal in 1977, a Prize of Mechanics from the French Academy of Sciences in 1982, the Max Planck Research Award for 2001 conferred by the German Federal Republic, and the SES Eringen Medal from the Society of Engineering Science, USA (2003). He has received honorary doctoral degrees from different countries, e.g., from the Lomonosov State University in Moscow, the Technical University of Darmstadt and the Aristotle University in Thessaloniki. He is a foreign member of the Polish Academy of Sciences, of the Estonian Academy of Sciences and a member of several professional societies (ASME, AMS, APS, ASA, SIAM, GAMM, ISIMM, ...). An international colloquium was held in his honor in Ann Arbor, Michigan, in 2003, and a Festschrift volume was published on that occasion with contributions from all over the world. He has been very much involved in cooperative programs at the European and international levels. He was selected as a member of the Wissenschaftskolleg zu Berlin in 1991-1992, as an invited visiting professor on the chair of innovative science at Kyoto University, Japan, in 1997-1998, and a Springer visiting professor at the University of California, Berkeley, for 2004-2005. Between 1977 and 2011, he taught in eight different courses at Udine's International Center of Mechanical Sciences (CISM) in Italy where he had participated in one of founding sessions as a student from North America in 1970.

Concerning his scientific achievements, G. A. Maugin was a pioneer in the development of the now fashionable multiphysics with a rational nonlinear electrodynamics of deformable continua and relativistic continuum thermomechanics (in Paris, under the influence of André Lichnerowicz, and at Princeton, under that of John A. Wheeler). Most of the former work now finds applications in electrical engineering and signal processing but also in the new technology of adaptive structures and so-called smart materials, while the latter works are still considered in astrophysics and the like. Some of these works were developed in cooperation with Bernard Collet, Joël Pouget, Anaclet Fomèthe, Naoum Daher, Shinya Motogi, A. Hakmi and J. Sioké-Rainaldy, with a special interest in coupled electro-magneto-elastic waves in various types of crystals and an emphasis on resonance effects (e.g., with his three Egyptian PhD students). As early as 1968, under the influence of Paul Germain, Gerald B. Whitham, Wallace D. Hayes and Martin D. Kruskal, he became interested in nonlinear waves and back in Paris created a group dealing with the propagation of nonlinear waves of different types (shocks, solitary waves, solitons) in solids in both discrete and continuous frameworks. Together with Estonian, Russian, Bulgarian and Ukrainian colleagues he participated in the construction of new classes of solutions in realistic physical models of deformable crystals. He also contributed to the theory of linear and nonlinear bulk waves and surface waves on solid substrates (with S. Cadet, J. Pouget, A. Miled, H. Hadouaj, A. N. Abd-Alla, A. F. Ghaleb, A. V. Porubov, C. I. Christov, A. Salupere, B. A. Malomed) and to the theory of wave propagation through multilayered and inhomogeneous structures (with V. Alshits). Following the French school of mechanics and also Joseph Kestin (Brown), he forcefully contributed to the formalization and some powerful illustrations of the thermomechanics of bodies with internal variables of state (with Wolfgang Muschik), including for solutions of macromolecules (with Raymonde Drouot and Angelo Morro) and hysteresis in ferromagnetics and ferroelectrics (with M. Sabir, A. F. Ghaleb and his co-workers), and some other modeling problems with J. Engelbrecht and A. Berezovski. He got involved in the homogenization of elastic 
and electro-elastic composites within cooperations with Nicole Turbé in Paris and Reinaldo Rodriguez-Ramos from Cuba.

Starting in 1989, together with Marcelo Epstein (Canada) and Carmine Trimarco (Italy), he was one of the most creative and never tired contributors to the theory of so-called configurational forces (driving forces on defects and inhomogeneities in a general manner) following the path opened by the pioneering works of J. D. Eshelby and the geometrical approach favored by Ekkehart Kröner. This led to revisiting some basic aspects of the theory of fracture (with Cristian Dascalu) and defects (with Markus Lazar and E. C. Aifantis). The last fruitful developments along this line were the application of the concept of "material force" to numerical schemes, the construction of a thermodynamically admissible numerical scheme of the volume element type in order to treat the propagation of phase transition fronts in solids (with A. Berezovski) and applications to the optimization of the finite element method (with R. Mueller and D. Gross). Another fruitful avenue has been fundamental contributions to the theory of material growth with applications to the mechanics of soft biological tissues (with Marcelo Epstein, Shoji Imatani, Sara Quiligotti, and then Pasquale Ciarletta, D. Ambrosi and L. Preziosi). The three essentials keywords in these works are "finite deformations," "structural rearrangements" and "nonlinearity," while the identified Ariadne's thread is the theory of invariants and conservation laws in the sense of Noether's theorems. The necessary background remains the general thermomechanics in a line that Pierre Duhem would not have disavowed.

Maugin's most recent subjects of interest are dynamic materials that are inhomogeneous both in space and time, the association of quasi-particles with wave modes in continua (with Martine Rousseau), and wave propagation in fractal materials (with Thomas Michelitsch). His long creative association with A. Cemal Eringen (Princeton) and his own conspectus views on this matter make that he kept a constant but critical interest in generalized continuum mechanics for which he is a much looked for expert. Although his scientific thinking was much influenced by the early reading of the book series on theoretical physics by L. D. Landau and E. M. Lifshitz, and obviously the seminal works of the Truesdellian School of continuum mechanics, with time he developed a wise good balance between formalism and pragmatism.

He has established longtime fruitful and friendly cooperations with scientists from the world over, e.g., Russia (Moscow, St Petersburg, Nizhny-Novgorod, Krasnodar, Samara), Ukraine (Kharkov), Estonia (Tallinn), Germany (Darmstadt, Kaiserslautern, Bremen, Erlangen, Stuttgart, Berlin), Sweden (Stockholm), Greece (Thessalonica, Ioaninna), Israel (Tel-Aviv, Haïfa), Italy (Genova, Pisa, Roma, Messina), Spain (Madrid, Barcelona), the UK (Nottingham, Cambridge, Edinburgh, Glasgow), Poland (Warsaw, Poznan), Canada (Calgary, Montreal, Victoria), Serbia (Belgrade, Kragujevac), Turkey (Istanbul, Ankara), Egypt (Cairo), Japan (Osaka, Kyoto), North Africa (Morocco and Tunisia), Cuba and the USA (Princeton, Berkeley, WashingtonDC, Lincoln-Nebraska, Lafayette-Louisiana). He has mentored a total of $38 \mathrm{PhD}$ or DSc students from many different countries and attracted to Paris post-doctoral scientists and visiting professors from all continents. He continued his scientific activities at the same pace as before in spite of heavy administrative duties in the period 1999-2009. Still he finds time to devote some more than amateurish interest to the history of science and epistemology, with a specific interest in Gabrio Piola, Pierre Duhem, Gustav von Helmholtz and the Cosserat brothers, not to forget his dear d'Alembert. He remains an aficionado of trains, real ones and models, although initially formed as an aeronautical engineer!

\section{More about the personality of Prof. Maugin in the form of interview}

We gather here the content of many conversations which we had the pleasure to have with prof. Maugin. He is a (sometimes too!) direct and opinionated man, whose knowledge spans humanities and many scientific fields. His English style maintains the clear fingerprint of a person whose mother language and education was French. He uses the English language as a modern Lingua Franca, without avoiding to use the linguistic constructions based on Latin. We enjoyed very much his brilliant wit and educated arguments.

What am I? (Qui Suis Je?):

A report of some conversations with Gérard A. Maugin in June 2013

Je suis moy-mesmes la matière de mon livre

(Michel de Montaigne, Les Essais, Envoy to the reader)

The question "Who are you?" considered as pertaining to an individual's identity, as asked by the police on in a court of justice, admits of a simple answer: "I am Gérard A. Maugin, born on December 02, 1944, Angers, Val-de-Loire, West of France; profession: scientist." 
The following question that relates to the definition of an object of study: "What are you (the above mentioned individual) from the standpoint of a professional scientist?" requires more pondering for receiving a truly meaningful answer.

Quite often during international symposia some people who meet me for the first time but who have heard of me, studied some of my papers, or read some of my books, ask me what is my formation, what are my main interests, and in short, what (not who), in reality, am I? They ask me those questions because some are a bit surprised by the thematic variety and the various styles of my published papers over a long span of time. First, it must be realized that, in the course of time (about 45 years), these papers were written with, in all, about fifty doctoral students, post-doctoral researchers, eminent visitors and active co-workers. This greatly reduces the very personal output although I always had a definite contribution in all papers published with co-workers. But it is true that this variety is puzzling.

\section{From mechanical engineer to mathematical physicist, or the reverse, or a mix?}

Therefore, I come myself to the point of asking me the same questions. The answers deal with the way in which one defines oneself's occupations in science. There are several possibilities.

\section{(a) Basing on the initial formation}

A first classification is possibly based on the initial formation of the person. But this can be misleading because of the evolution of the person in time, an evolution that can put some large distance between the original diploma and the actual occupation. This we can illustrate with the case of Henri Poincaré. Who would define him now as a mining engineer, even though this may have been his formal title after his formation at the École Polytechnique and a specialization (obviously not dictated by personal taste) at the Paris School of Mines? To give other examples related to engineering, we recall that both Joseph and Johann Strauss of musical fame were educated as "civil engineers" at the Imperial-Royal Polytechnic Institute (for short in German KKPI) in Vienna, while the two American novelists of Nobel-prize caliber, Norman Mailer and Thomas Pynchon, were-like the present author-both educated as aeronautical engineers. This last coincidence may have nurtured my inclination to literary expression.

\section{(b) Basing on the professional affiliation}

Another possibility is to categorize one person by his actual professional affiliation to a special type of university department. This may also be misleading. To support this judgment, we can consider the case of scientists who, in Italy, for some historical reasons are officially members of Departments of Civil Engineering ("Scienza delle Costruzioni"), but who, in research practice, are but applied mathematicians. There are historical explanations for this situation if we remember that many mathematical methods developed in the nineteenth century, and later on justified by purer mathematics, find their origin in the solution of problems posed in mechanical and civil engineering. A rather similar situation took place in France for quite a long time when teaching rational mechanics was often delivered by true analysts while waiting for a real chair in mathematics. This may not be so strange if we remember Gustave Flaubert's definition of mechanics in the Dictionary of "Idées reçues" (generally accepted ideas) as the "lowest branch of mathematics," an idea that was still expressed with some condescendence a short time ago by Jean Dieudonné, the French mathematician most influential in the Bourbaki group. One may also wonder how to classify Archimedes and Leonardo da Vinci? We may think of them as "military engineers" (as opposed to civil engineers) since they both conceive of war machines for their mentors. But we must emphasize that Archimedes was rather an applied physicist (see his famous "principle") and Leonardo a supreme artist (his painting), and both were acute observers of nature.

In a much thoughtful short biographical sketch, I have given of myself a description as "a French mechanical-aeronautical engineer with an American education and a marked interest in mathematical physics" to which I can add "and also in the history of science and the evolution of ideas." This practically contains all good ingredients for a satisfactory definition: the initial formation, what mostly influenced the scientific practice, and the immediate side interests. Of course I am no professional historian of science. Neither am I a true philosopher, since true philosophers create new (philosophical) concepts (Note for my apology that there are very few "true" philosophers.). This is not my case. But perhaps that I am a "philosopher of nature" (i.e., a physicist) in the eighteen's century meaning. For sure I am some kind of mathematical physicist in the same way as I may require to be called a "mechanician" and an "acoustician" (see below). 


\section{(c) According to membership in professional societies}

Still there are other possibilities, for instance, to what scientific societies does a scientist belong? This, in principle, should correspond to his tastes, practice and the media in which he feels most at ease and in resonance with. In my case. I have been a longtime member of

- the American Mathematical Society (AMS);

- the Society of Industrial and Applied Mathematics (SIAM, USA);

- the Gesellschaft für angewandte Mathematik und Mechanik (GAMM, Germany);

- the American Society of Mechanical Engineers (ASME, USA);

- the American Physical Society (USA);

- the Acoustical Society of America (ASA, USA);

- the Society of Engineering Sciences (International but mostly American).

I am not a true (pure) mathematician although I was well trained in mathematics (applied functional analysis, differential geometry). Accordingly, the second society is more appropriate since I was already invited to deliver general lectures at some meetings organized by that society. This is also the case of GAMM which has the property to unite applied mathematics and mechanics, which seems to be in perfect agreement with most of my scientific activity. Note in passing that G.A.M.M (!) is also the full set of my initials. I participated in meetings of the ASME but seldom published in its journals. My belonging to the Physical Society seems to be justified in view of my numerous contributions in its journals, "Physical Review" and the "Journal of Mathematical Physics," and the many referee reports written for its journals. I have published about twenty papers in the journal of the ASA. As to the SES, I published about forty-five papers in its journal and was honored by a special symposium of the society in Ann Arbor when I reached 60 years of age.

\section{(d) According to the favorite place of publication}

In view of these, the place of publication of research papers may be the best indicator of the "definition" of a scientist, independently of the official name of the institute to which he is affiliated. This is how I defined a group of American scientists as "mechanical engineers" in my historical perusal of the development of continuum mechanics through the twentieth century, ${ }^{1}$ because they identified themselves with the spirit of the A.S.M.E and often published in its journals. In my case, in the interval of 1970-1990, half (i.e., forty out of eighty) of my papers were published in journals of physics or mathematical physics (essentially in the USA and the UK) and the other half in journals of engineering sciences and applied mathematics. But a clear inclination toward the second avenue was already showing that would yield the final result enunciated in paragraph (e).

\section{(e) An external objective categorization}

Finally, I recently found a nice way to label the published works of a scientist (in particular in my case, over a sufficiently long period). This is the categorization made (I do not known through what procedure) among large classes of papers in the Web of Science. Concerning my case, among 338 items recorded by this institution, the distribution was as follows on October 18, 2012:

- Mechanics (154 items),

- Engineering multidisciplinary (52 items),

- Physics multidisciplinary (48 items),

- Acoustics (40 items),

- Materials science multidisciplinary (32 items),

- Others (12 items).

We see that "Mechanics" and "Engineering multidisciplinary" (what essentially means "theoretical continuum mechanics" and couplings between continuum mechanics and applied physics) represent about $60 \%$ of the whole, while "physics" (what predominantly means "mathematical physics") stands for $14 \%$ (theoretical), acoustics for less than $12 \%$ and "Materials sciences" for less than $10 \%$. All these figures are to be considered with some caution. The reason for this is that many problems considered in all categories are connected

\footnotetext{
${ }^{1}$ G. A. Maugin (2013), see the Appendix in Continuum mechanics through the twentieth century-a concise historical perspective, Springer, Dordrecht-New York.
} 
with dynamics and the propagation of linear or nonlinear waves, so that (physical) "Acoustics" is very much underestimated. Also, many of the papers in four of the categories indeed relate to the "thermomechanics" of continua. Finally, the spirit of mathematical physics permeates all papers through variational formulations, application of group-theoretical methods, space-time formalism, etc. But the "multidisciplinary" attached to several of the above given categories is also a mark of a certain type of works, most of them partaking of continuum mechanics, applied mathematics, and a strong physical background. I find this adequate enough. Note that this is not being a polymath because all works are in fact related to the same large field, phenomenological physics, although a constant interest in the comparison between discrete and continuous descriptions is present (e.g., in soliton theory, consideration of quasi-particles, lattice dynamics).

And who is he to us? A man of an extremely vast scientific, historical and artistic curiosity. Being avid of knowledge he has been also privileged by an excellent memory, a good sense of analysis and a real critical capacity. Not much interested by sportive activities, long walks in the countryside or refined meals, he much prefers discussing various subjects along with a simple dish, especially if he appreciates the company around him. He is always fond of a short and amusing story with a touch of humor! However, he is a man of forceful personality that can take a sharp position on some points especially if they bother him. A sincere man, faithful to friendship, who will willingly listen to the people in his surrounding who know they can always rely on his discretion, his friendly advises and his generosity. We conclude with the citation from "Les caractères" by Jean de la Bruyère depicts quite well-in our opinion-Gérard Maugin 's ways of managing his career as a scientist. "La liberté n'est pas oisiveté; c'est un usage libre du temps, c'est le choix du travail et de l'exercice. Etre libre, en un mot, n'est pas ne rien faire, c'est être seul arbitre de ce qu' on fait ou de ce qu'on ne fait point. Quel bien en ce sens que la liberté!"

\section{Personal Acknowledgments}

The three guest editors of the special issue honoring Prof. Maugin on occasion of his 70th birthday would like to thank first of all Gérard Maugin himself. In different moments of their academic life, they could exploit his scientific and personal support, who motivated them to continue and better their efforts in scientific research. The generosity of Prof. Maugin is witnessed by the huge amount of scientists who admit to have been his pupils.

Obviously a special thanks must be reserved to Prof. Kienzler, who made this issue possible and whose invaluable advice was very precious in many circumstances. Finally, the efforts of all authors must be recognized: The peer-reviewing process was kept at the highest standards also in this occasion, and all authors were very careful and attentive to meet them. 